\title{
Amerikan Merkez Bankası Faiz Kararları İle BIST 100 Endeksi Arasındaki İlişkinin Belirlenmesi
}

\author{
Meltem KESKIN KÖYLÜ*
}

Ahmet YÜCEL**

\begin{abstract}
$\ddot{O Z Z E T}$
Çalışmada, Amerikan Merkez Bankası görevini yerine getiren Federal Rezerv Sistemi'nin sıkı veya genişletici para politikası dönemlerinde aldığ faiz kararlarının Borsa İstanbul Pay Piyasasında kullanılan temel endekslerden biri olan BIST 100 endeksine yaptı̆̆ etki incelenmiştir. Çalışmada kullanılan veri seti 04.01.1988 ile 06.08.2018 tarihleri arasını kapsamaktadır. Bu çalışmanın amacı; Federal Rezerv Sistemi'nin aldığı faiz indirimi veya artırımı kararlarının Borsa Istanbul'da işlem gören hisse senetleri fiyatları arasında ilişkinin varlığını, yönünü ve boyutunu belirlemektir. Bu tespiti yapabilmek için sınıflama ve regresyon karar ağaçları analizi kullanılarak model oluşturulmuştur. Federal Rezerv Sistemi faiz oranlarındaki değişimin BIST 100 endeksi üzerinde ne yönlü etki yaptığı saptanmıştır. Sonuç olarak, Federal Rezerv Sistemi’nin açıkladığı faiz oranının BIST 100 endeksi üzerindeki etkisi bir sonraki işlem günü için sinırlı kaldığı, bir haftalık işlem sürecinde etkisinin belirginleştiği ve zaman ilerledikçe bu etkinin azalarak bir sonraki Federal Rezerv Sistemi'nin faiz. oranları açıklamasına kadar devam ettiği gözlemlenmiştir.
\end{abstract}

Anahtar Kelimeler: Federal Rezerv Sistemi, Faiz Kararları, Borsa İstanbul, BIST 100 Endeksi.

JEL Sinıflandırması: E40, E44, F30, G00.

\section{Determination of The Relationship between The Federal Reserve Board Interest} Rates and BIST 100 Index

\section{ABSTRACT}

In the United States of America, the interest rate decisions are taken by The Federal Reserve System, which serves as the Federal Reserve System in tight or expansionary monetary policy periods, In this study, the effect of the Federal Reserve System interest decisions on BIST 100 index, which is one of the main indices used in Borsa Istanbul, is examined. The dataset used in the study is gathered in period of 04.01.1988-06.08.2018. The aim of this study is to determine the existence, direction and size of the relationship between the interest rates issued by the Federal Reserve System and the stocks prices traded in Borsa Istanbul. In order to make this determination, a decision model based on classification and regression tree analysis was utilized. The effects of the Federal Reserve System interest rate changes on BIST 100 index were determined. As a result, the effect of the Federal Reserve System on the BIST 100 index was inconsiderable in the next trading day, in the next one-week trading period the effect becomes evident, and until the next Federal Reserve System interest rate issues this effect continues decreasingly.

Keywords: Federal Reserve System, Interest Decisions, Borsa Istanbul, BIST100 Index.

Jel Classification: E40, E44, F30, G00.

\footnotetext{
* Dr. Öğr. Üyesi, Ankara Yıldırım Beyazıt Üniversitesi, Şereflikoçhisar Uygulamalı Bilimler Fakültesi, mkeskinkoylu@ybu.edu.tr. Orcid ID: 0000-0002-8536-4940.

** Dr. Öğr. Üyesi, Ankara Yıldırım Beyazıt Üniversitesi, Şereflikoçhisar Uygulamalı Bilimler Fakültesi, ayucel@ybu.edu.tr. Orcid ID: 0000-0002-2364-9449.
} 


\section{GíRISS}

Osmanlı döneminde borsa; Dersaadet Tahvilat Borsası ile başlayıp ve 1906 yılında Esham ve Tahvil Borsası adı ile devam eden borsa Türkiye Cumhuriyeti döneminde; 1929 yılında kabul edilen 1447 sayılı Menkul Kıymetler ve Kambiyo Borsaları Kanunu ve 8172 sayılı nizamname ile İstanbul Menkul Kıymetler Borsası adı ile çalışmaya başlamıştır. 1938 yılında Borsanın merkezi İstanbul'dan Ankara'ya taşınarak adı Esham ve Tahvilat Borsası olarak görevine devam etmiştir. Borsa, 1941 yılında tekrar İstanbul'a nakledilmiştir. 06 Eylül 1983 yılında Menkul Kıymetler Borsaları hakkında 91 sayılı Kanun Hükmünde Kararname ile 1447 sayılı kanun yürürlükten kaldırılmıştır. 26 Aralık 1985 yılında İstanbul Menkul Kıymetler Borsası (İMKB) işlem görmeye başlamıştır. İlk seansı 03 Ocak 1986 tarihinde gerçekleşmiştir. Borsa İstanbul (BIST) 30 Aralık 2012 tarihinde 6362 sayılı Sermaye Piyasası Kanunu'na dayanarak İMKB'nin yerini almıştır. Bu değişiklikle birlikte Türkiye'de faaliyet gösteren tüm borsalar bir çatı altında toplanmıştır. 5 Nisan 2013 tarihinde ilk seansına başlamıştır.

Çalışmanın verilerinin bir kısmı 04.01.1988-04.04.2013 tarihleri arasında kullanılan İMKB 100 endeksinden sağlanmıştır. IKKMB 100 endeksi; ulusal pazarda işlem gören şirketlerin belirli ölçütler çerçevesinde İMKB tarafından ilk 100 sırada yer alan hisse senetlerinden oluşturulmuş bir endekstir. Bu endeksin içerisinde İMKB Ulusal 30 ve İMKB Ulusal 50 hisse senetleri endeksleri de yer almaktadır.

BIST 100 Endeksi; Yıldız Pazar ve Ana Pazar'da işlem gören şirketlerle, Kolektif Yatırım Ürünleri ve Yapılandırılmış Ürünler Pazarı'nda işlem gören gayrimenkul yatırım ortaklıkları ve sermayesi yatırım ortaklıkları içerisinden listelenmiş 100 paydan oluşmaktadır. $\mathrm{Bu}$ endeks içerisinde BIST 30 ve BIST 50 endeksleri de yer almaktadır (Borsa İstanbul, 2016: 4).

Amerikan Merkez Bankası (FED) aldığı para politikası kararları ile sadece kendi ülke ekonomik çevresini değil dünyayı da etkileyebilecek öneme sahip organizasyondur. FED'in aldığı faiz indirim/artırım kararları da gelişmiş ve gelişmekte olan ülkelerin finansal piyasalarında da karşılık bulabilmektedir. Çalışmada FED'in 1988 yılından 2018 yılının sekizinci ayına kadar olan faiz ile ilgili kararları FED'in resmi sitesinden sağlanmıştır.

Çalışmada sınıflama ve regresyon karar ağacı algoritması kullanarak model oluşturulmuş ve FED faiz kararlarını açıkladığı tarihleri içerisine alan kısa ve uzun dönemli olarak BIST 100 endeksi ile karşılaştırılmıştır.

\section{LITERATÜR TARAMASI}

Finansal piyasaların temelini oluşturan borsalar yatırımların birikime dönüşmesini sağlayan sermaye piyasalarının temel kurumlarıdır. Sermaye piyasalarının başlıca finansal araçlarından biri ise hisse senetleridir Aydın vd., (2012). Uluslararası borsa olan BIST, ekonomiye likidite ve kaynak sağlamanın yanı sıra mülkiyetin halka yayılmasını sağlayan önemli finansal görevleri yerine getirmektedir (Şahin, 2014: 13-14).

Literatürde hisse senetlerinin döviz kurları ile etkilendiği ile ilgili pek çok çalışmaya rastlanmıştır. Dornbush ve Fischer, (1980) döviz kuru ve hisse senetlerinin etkileşimini nedensellik olarak açıklayan araştırmacılardan biridir. Yine bu ilişkiyi portföy denge 
yaklaşımı ile (Frankel,1983)'de yaptığı çalışmada açıklamıştır. Uzun yılar içerisinde konuyla ilgili olarak ulusal ve yabancı araştırmacılar portföy dengesi yaklaşımı ve geleneksel yaklaşımla ilgili konuyu araştırmışlardır. Yapılan araştırmaların çoğunda döviz piyasaları ile hisse senedi arasında belli düzeyde ilişki bulunmuştur ancak Bahmani, Oskooee ve Sohrabian (1992) ve Zhao (2010) ise uzun dönemli bir ilişki olmadığını tespit etmiştir (Büberkökü, 2008: 2-3). Bu çalışmaların yanı sıra yabancı portföy yatırımlarının hisse senetleri üzerinde etkileri de araştııılmıştır. Yabancı yatırımların ekonomiye etkileri, hisse senedi fiyatları ve fiyat dalgalanmaları üzerine etkileri, yabancı sermayenin geldiği borsaya ve hisse senetlerinin gelişimine etkileri gibi birçok grupta yapılmış yüzlerce çalışma mevcuttur (Gümüş, 2010: 6367). $\mathrm{Bu}$ çalışmalara burada yer verilmemiştir. Haftanın belirli günlerinde, hisse senetleri değerlerinde oluşan değişim de bir diğer araştırma konusudur. Fields (1931)'de Dow Jones Sanayi Endeksi 1918-1930 yıllarını baz aldığı çalışmasında hisse senetlerinin Cuma günleri yükselme eğiliminden olduğunu belirtmiştir. Lucey (2000) çalışmasında hisse senetleri fiyatlarının haftanın günlerine göre değişim gösterdiğine ve bu etkinin 1930 yıllarında da bilindiğine vurgu yaparak Fields'in çalışmasına gönderme yapmıştır. Bu kapsamdaki araştırmalar pek çok yabancı araştırmacının ilgi alanına girdiği gibi Türkiye'de de hem İMKB hem de BIST 100 endekslerinde bu yönlü çalışmalara rastlanmaktadır. Çalışmaların genelinde, hafta başına rastlayan günlere ait getirilerin hafta sonuna yakın günlerden daha düşük olduğuna yönelik bir eğilim görülmüştür.

Haftanın günlerinin hisse senetleri getirilerine olan etkisi üzerine yapılan çalışmalar gibi İMKB ve BIST ile ilgili literatürde pek çok grupta çalışma bulunmaktadır. Bunlardan bazıları aşağıdaki gibidir.

Foan (2006) çalışmasında, 2000 yılı ile 2004 yılı arasında IMKB 30 verileri kullanmıştır. Yatırımcıların ortalama risk üslenerek maksimum getiriyi sağlayacak bir portföy oluşturmaları için temel ve finansal analizle seçimlerini sınamaları ve teknik analizle getirilerini artırmaları için model oluşturacağına vurgu yapmıştır. Sayman (2006) çalışmasında İMKB'de işlem gören imalat işletmeleri için 1992-2004 yılları arasındaki likidite tepkileri panel veri analizi kullanılarak araştırılmıştır. İşletmenin büyüklükleri, finansal açıdan sınırlılık düzeyi, aktiflerin getiri oranı, karlılık ve borcun vade yapısı ile işletmelerin varlıkları arasında bulundurdukları nakit arasında pozitif yönlü bir ilişki bulmuştur. Akbulut ve Rençber (2015) çalışmalarında Borsa İstanbul'da işlem gören otuz iki işletmenin finansal performansları ile defter değeri oranı arasındaki ilişki araştırılmıştır. Topsis yöntemi ile değerlendirilen çalışmada performans ile defter değeri arasında ilişki olmadığı sonucuna ulaşmışlardır. Tokmakçığlu, (2017: 113) yaptığı çalışmada, Türkiye gibi gelişmekte olan pazarlarda kısmen yüksek piyasa risklerinin olması nedeni ile yatırımcıların çeşitlendirmenin volatilitenin en aza indirilmesinde yararlı olduğuna vurgu yapmışlardır. Ayrıca Varlık, (2017) çalışmasında, spektral analiz tekniğiyle, Borsa İstanbul'daki hareketleri incelemiştir. BİST 100 endeksinde görülen dalgalanmaların rastgele değil, belli periyotları olan dalgalanmalar olduğuna vurgu yapılarak yatırımcıların bu salınımları yorumlayarak yatırım yapmalarına imkân sağlanabileceği hakkında görüş geliştirilmiştir.

Hisse senetleri fiyatlarının faiz hareketliliği ile kısa dönemde kısmen etkilendiği gözlenebilmektedir. Ancak bu etkinin yalnızca faiz oranları değil para politikası araçlarından herhangi birinden veya tümünden de etkilenmesi söz konusu olabilmektedir. Ayrıca sosyoekonomik faktörlerde hisse senetleri fiyatları üzerinde etkiye neden olabilmektedir. Thorbecke (1997), FED'in kararlarının hisse sentleri üzerine etkisini incelemiştir. Lobo 
(2000), faiz artırımının hisse senetleri fiyatları üzerine etkisinin kısıtlı kaldığı kanaatine ulaşmıştır. Rigobon ve Sack (2004), Amerika Birleşik Devletleri'nde (ABD) hisse senedi fiyatlarının kısa vadede faiz artışlarından etkilendiğini belirlemişlerdir. Yine aynı yıl, Bernanke ve Kuttner (2004), FED'in önceden tahmin edilmeyen 25 baz puanlık faiz indirimi borsa endeksinde yaklaşık \%1 oranında artışa neden olduğunu beklenmeyen para politikası değişikliklerinin hisse senetleri endekslerinde oynamalar yarattığını vurgulamışlardır. Hayford ve Malliaris (2008), 1990 sonrası FED'in faiz artırım/indirim yönlü kararlarını önceden piyasalara açıkladığı için olayın gerçekleşmesi aşamasında borsa endekslerinin tepki vermediği sonucuna ulaşmışlardır. Ancak Kashefi (2008), faiz indiriminin hisse senetleri endeksinde artışa neden olduğu sonucuna ulaşmıştır. Grauwe (2008) merkez bankalarının faiz politikalarının hisse senedi fiyatlarına da etki yaptığını çalışmasında vurgulamıştır. Ehrmann ve Fratzcher (2009), FED faiz artırım politikasının sonucu hisse senetleri fiyatlarının geri çekildiği sonucuna ulaşmışlardır. Duran vd. (2010), 20085-2009 yılları arasında Türkiye'de yaptıkları çalışma sonucunda politika faizlerindeki artışların, hisse senedi fiyatlarını negatif etki yaptığını tespit etmişlerdir. Şahin (2011), 2005-2010 yılları arasını kapsayan çalışmasında para politikası kararlarının İMKB 100 endeksi üzerine etkilerini incelemiştir. Para politikasında beklenmeyen değişimlerin hisse senedi fiyatları üzerinde etkili olduğunu sonucuna ulaşmıştır. Etkinin ise sektörlere göre farklılaştığını da tespit etmiştir. Lee ve Chang (2011), Tayvan borsasında yaptıkları çalışmada faiz değişikliklerinin hisse senetleri üzerinde anlamlı değişikliğe neden olduğu sonucuna varmışlardır. Bleich vd. (2013) İngiltere, Amerika, Japonya ve Avrupa Merkez Bankası'nın, faiz azalış ile hisse senetleri fiyat ilişkisini incelemişler. Faiz indirimlerinin bahsi geçen ülkelerde hisse senetleri fiyatlarında volatiliteye neden olduğunu belirlemişlerdir. Zare, Azali ve Habibullah (2013), faiz artışlarının etkilerini, Malezya, Endonezya, Singapur, Filipinler ve Tayland borsalarında incelemişler. Sonuç olarak, ayı piyasasında etkinin boğa piyasasına göre uzun dönemde daha etkili olduğunu çalışmalarında belirtmişler. Michlian (2014), Çek Cumhuriyeti'nde kriz dönemlerinde faiz oynaklıklarının hisse senetlerine etkisini incelemiş ve anlamlı bir ilişki bulamamıştır. Çelik vd. (2015) merkez bankalarının sözlü yönlendirmelerinin BIST 100 üzerine etkilerini 20022014 arasında test etmişlerdir ve bu sözlü yönlendirmelerin etkili olduğu konusunda güçlü bulgulara ulaşmışlardır. Godollo ve Pecs (2018), 2010-2017 yılları arasında literatürde yer alan 67 makaleyi inceleyerek faiz hareketleri ile hisse senedi piyasası alanındaki mevcut farkları tanımlaya çalışmışlardır. Literatür incelendiğinde FED'in aldığı faiz artırım/indirim kararlarının BIST 100 endeksinde incelenmesi ile ilgili herhangi bir çalışmaya rastlanmamıştır.

$\mathrm{Bu}$ çalışmada yer alan metodolojinin de temel motivasyonu olan, Heiberger (2017) çalışmasında bir kredi derecelendirme kuruluşu olan Standard and Poor's 500'den temin ettiğgi, Amerikan ekonomisinin 1988-2016 yılları arasındaki dalgalanmalarını konu alan bir veri seti üzerine öngörü modeli oluşturmuştur. Çalışmada ikili karar (Bayesian) yaklaşımı uygulanmıştır. Buna ek olarak, Amerikan borsalarında işlem gören bazı şirketlerin pozisyonlarını da öngörü modelinde bir gösterge faktörü olarak kullanmıştır. Bu sayede oluşturulan model ile ekonomideki bir yıl sonraki gerçekleşmesi muhtemel senaryoları başarılı şekilde öngörebilmiştir. 


\section{METODOLOJI VE VERI}

\subsection{Sınıflama ve Regresyon Karar Ăgaçları (C\&RT)}

Regresyona dayalı olasılık hesabı ile ikili (binary) sınıflama yapan karar ağacı, her kararın bir sonuç dügüumü ile ifade edildiği ağaç formlu modeldir. Toplanan sürekli ve kesikli veriler, algoritmalar aracılığıyla olasılık verilerine dönüştürülür ve bu sayede karar dügümleri oluşturulur. Kök düğüm algoritması tek bir değişkene göre hesaplanır ve en tepede yer alır. Kök düğüm dâhil tüm oluşan dügümler dallara ayrılırlar. C\&RT düzenli veri bölünmeleri ile yukarıdan aşağıya gelişen ağaç görünümünü oluştururlar. Ağaç çapraz doğrulama ile büyür ve bağımlı değişken ile ilişkili olan verilerin kullanılabilmesi için budama modeli kullanılarak bağımlı ve bağımsız değişken arasındaki ilişki belirlenir. Leo Breiman ve çalışma arkadaşlarının 1984'de geliştirdiği Sınıflama ve Regresyon Karar Ağacı Modeli, Finans, ekonomi, bilgisayar, sağlık, risk yönetiminden makine öğrenmesine kadar pek çok uzmanlık alanında kullanılmaktadır.

Karar ağacı algoritmaları uygulaması ve yorumlamasının kolaylığı nedeni ile birçok tahmin probleminde yaygın olarak kullanılmaktadırlar. Karar ağaçlarını kullanarak sınıflama süreci özetle şu şekilde ifade edilebilir: Öncelikle mevcut veri kontrol ve test alt gruplarına ayrılır. Bu alt grup, kontrol grubundan bağımsız rasgele örneklemeye dayalı ve homojen olarak oluşturulur. Bu şekilde, her bir bağımsız değişkenin bağımlı değişken üzerindeki etkisi ölçülür. Bu süreç sabit bir karar değerine ulaşana kadar sürdürülür (Yücel, 2016: 22).

\subsection{Veri}

Çalışma kapsamında FED faiz oranları 04.01.1988 - 06.08.2018 tarihleri arasında incelenmiş ve veriler FED'in resmi sitesinden elde edilmiştir. Bu veriler grafik olarak Şekil 1 'de verilmiştir.

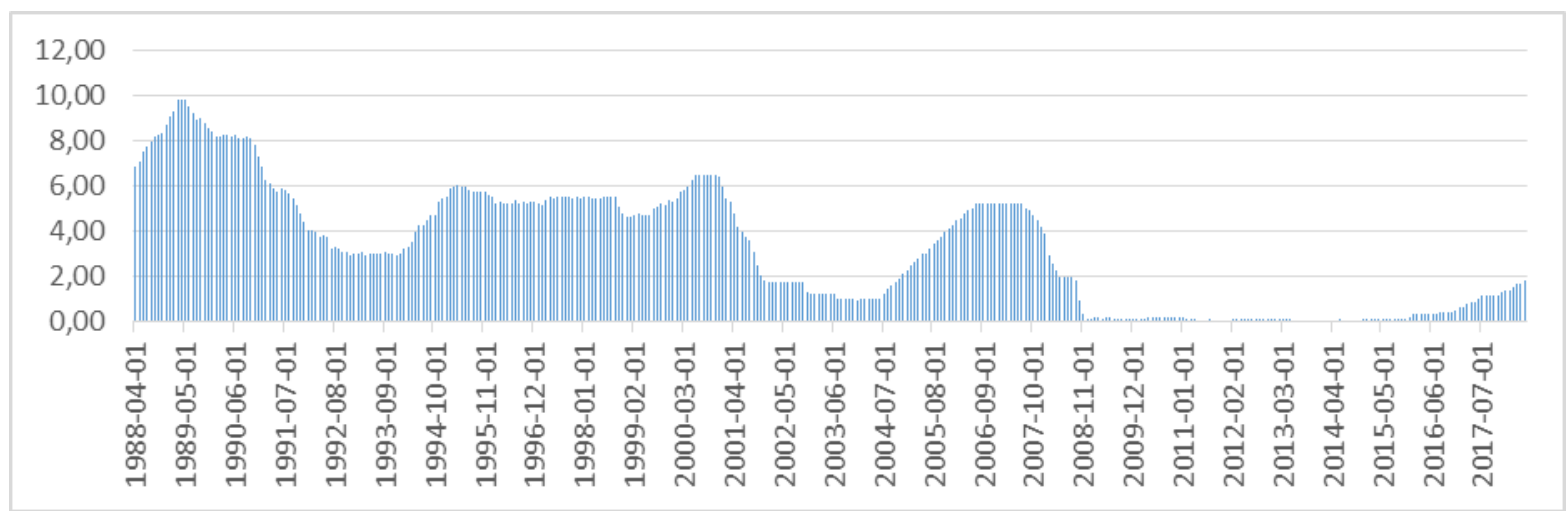

Kaynak: (www.federalreserve.gov/monetarypolicy/openmarket.htm, 2019)

Şekil 1. FED Faiz Oranları

Çalışmada yer alan BIST100 hisse senetlerini ait veriler ise, Borsa İstanbul A.Ş.nin verilerinin dağıtılması ve yayınlanması konusunda yetkilendirdiği kuruluşlardan sağlanmıştır. 


\section{AMPIRIK BULGULAR}

$\mathrm{Bu}$ çalışmada, mevcut veriler kullanılarak FED faiz oranları ile BIST100 oranları arasındaki ilişkinin düzeyi ve yönü belirlenmektedir. Bu amaçla, ilk olarak ilgili veri içinde yer alan temel istatistikler incelenmektedir. BIST 100 verileri (IMKK 100 dahil) 04.01.1988 06.08.2018 tarihleri arasında, resmi tatil günleri hariç, gün gün bulunmasına karşın, FED faiz oranlarına ait veriler, aynı tarihsel dönemde, düzensiz aralıklarda bulunmaktadır. Herhangi iki FED faiz oranı değişikliği ilanları arasında yaklaşık ortalama 88 gün bulunmaktadır. Bunun yanında, Tablo 1'de gözlemlenebileceği gibi FED faiz oranları değişikliğini en az 6 gün, en çok 1764 gün arayla yapmıştır.

Tablo 1. FED faiz oranları açıklama sıklı̆̆ı istatistikleri

\begin{tabular}{|c|c|c|c|c|}
\hline \multirow{2}{*}{$\begin{array}{c}\text { FED PERIYOT } \\
\text { (GÜN) }\end{array}$} & Ortalama & Ortanca & En Az & En Çok \\
\cline { 2 - 5 } & 88,252 & 32 & 6 & 1764 \\
\hline
\end{tabular}

FED faiz oranlarının BIST100 üzerindeki etkileri gözlemlemek için, veri üç aşamada incelendi. Birinci aşamada, FED faiz oranlarının açıklandığı tarihten sonraki BIST100 ilk işlem günü verileri (BIST100_Change_1Day)incelendi. İkinci aşamada, FED faiz oranlarının açıklandığı tarihten sonraki BIST100 beş işlem günü verileri (BIST 100_Change_1Week)incelendi. Üçüncü aşamada ise, herhangi iki FED faiz oranlarının açıklandığ 1 tarihler arasındaki tüm BIST100 işlem verileri (BIST100_Change_Until_Next)incelendi. Ek olarak, FED faiz oranları (Fed_Funds_Rate) ve açılanan her bir FED faiz oranının bir önceki orana göre değişim oranları (Fed_Rate_Change), çalışmada bağımlı değişkenler olarak incelenmiştir. Değişkenler süreklidir ve tüm bu değişkenlere ait istatistiksel verileri Tablo 2'de sunulmaktadır.

Tablo 2. Değişkenlere ait istatistikler

\begin{tabular}{|l|c|c|c|c|}
\hline Değişken & Ortalama & En Az & En Çok & Std.S. \\
\hline Fed_Funds_Rate & 4,097701 & 0,250000 & 8,250000 & 1,951578 \\
\hline Fed_Rate_Change & $-0,048851$ & $-0,750000$ & 1,000000 & 0,377105 \\
\hline BIST100_Change_1Day & 0,006063 & $-0,327800$ & 0,381400 & 0,073606 \\
\hline BIST100_Change_1Week & 0,001662 & $-0,048760$ & 0,139700 & 0,022931 \\
\hline BIST100_Change_Until_Next & 0,004758 & $-0,017650$ & 0,092967 & 0,014395 \\
\hline
\end{tabular}

FED faiz ve BIST100 günlük değişim oranlarının aşağ1/yukarı (0/1) yönlü hareketleri arasındaki korelasyonu gözlemlemek için, BIST100_Change_1Day, BIST100_Change_1Week, BIST100_Change_Until_Next ve Fed_Rate_Change değişkenlerinden, sırasıyla ikili (binary) değişkenler; BIST1Day_01, BIST1Week_01, BISTNext_01 ve Fed_Change01 oluşturulmuştur. İlgili değişkenlerin aşağ yönlü (0) ve yukarı yönlü (1) olduğu gün sayıları Tablo 3.'de verilmektedir.

Tablo 3. İkili kategorik değişkenlere ait frekans dağılımları

\begin{tabular}{|c|c|c|c|c|}
\hline & Fed_Change01 & BIST1Day_01 & BIST1Week_01 & BISTNext_01 \\
\hline $\mathbf{0}$ & 47 & 43 & 43 & 25 \\
\hline $\mathbf{1}$ & 40 & 44 & 44 & 62 \\
\hline
\end{tabular}


$\mathrm{Bu}$ çalışmada, FED faiz oranlarındaki değişim ile BIST100 günlük değerleri arasındaki ilişkinin düzey ve yönü gözlemlenmektedir. Bu amaçla, mevcut ve oluşturulan değişkenler kullanılarak bir C\&RT model oluşturulmaktadır. Oluşturulan modele ait bağımlı değişken Fed_Change01 olarak belirlenmiştir. Bağımsız değişkenler ise BIST 100_Change_1Week, BIST100_Change_1Day, BIST100_Change_Until_Next, BIST1Week_01, BIST1Day_01, BISTNext_01 olarak belirlenmiştir. Bağımsız değişkenlerin model içinde yaptıkları katkıya dayalı olarak, değişken önem sıralaması Tablo $4^{\text {‘de }}$ verilmektedir.

Tablo 4. C\&RT Modeline ait değişkenlerin önem sıralaması

\begin{tabular}{lcc}
\hline Variable & Rank & Importance \\
\hline BIST100_Change_1Week & 100 & 1,000000 \\
BIST100_Change_1Day & 89 & 0,886773 \\
BIST100_Change_Until_Next & 54 & 0,541420 \\
BIST1Week_01 & 37 & 0,371185 \\
BIST1Day_01 & 20 & 0,202556 \\
BISTNext_01 & 3 & 0,030291 \\
\hline
\end{tabular}

İlgili değişkenlerin önem sıralaması, sürekli değişkenlerin modele olan katkısının sınıfsal değişkenlerden daha fazla olduğunu göstermektedir. Bunun yanında, BIST 100 üzerindeki FED etkisinin, bir sonraki iş günü oldukça sınırlı olduğu, ancak bir haftalık periyotta bu etkinin daha belirginleştiği ve sonrasında azalmaya başladığı Tablo 4'deki sonuçlardan açıkça gözlemlenmektedir. C\&RT modeline ait karar grafiği Şekil 2'de ve değişkenlere dayalı karar aralıkları ve karar değerleri Tablo 5'de verilmektedir. Modelde toplam 5 (terminal) sonuç karar bulunmaktadır ve 3., 7. ve 9. adım kararlar oldukça yüksek doğruluk olasılığına dayalı olarak verilmiştir. $\mathrm{Bu}$ durum modelin güvenilirliğini göstermektedir.

Tablo 5. C\&RT Modeli karar verme dağılımı

\begin{tabular}{|c|c|c|c|c|c|c|c|c|c|c|}
\hline & \multirow{2}{*}{\begin{tabular}{|c|} 
Number \\
(of nodes)
\end{tabular}} & \multirow{2}{*}{\begin{tabular}{|c|} 
Size \\
(of node)
\end{tabular}} & \multicolumn{2}{|c|}{$\mathbf{N}$} & \multirow{2}{*}{\begin{tabular}{c|} 
Selected \\
(category)
\end{tabular}} & \multirow{2}{*}{\begin{tabular}{c|} 
Split \\
(variable)
\end{tabular}} & \multicolumn{2}{|c|}{ Criterion } & \multicolumn{2}{|c|}{ Child } \\
\hline & & & class $(0)$ & class $(1)$ & & & (child 1) & (child 2) & (node 1) & (node 2$)$ \\
\hline 1 & \begin{tabular}{|l|}
2 \\
\end{tabular} & 70 & 40 & 30 & 0 & BIST_1Day & $\mathrm{x}<=0,026$ & $x>0,026$ & 2 & 3 \\
\hline 2 & 2 & 56 & 27 & 29 & 1 & BIST_1Day & $x<=-0,041$ & $x>-0,041$ & 4 & 5 \\
\hline 4 & & 10 & 8 & 2 & 0 & & & & & \\
\hline 5 & 2 & 46 & 19 & 27 & 1 & BIST_1Week & $\mathrm{x}<=0,011$ & $x>0,011$ & 6 & 7 \\
\hline 6 & 2 & 41 & 15 & 26 & 1 & BIST_1Week & $\mathrm{x}<=0,002$ & $x>0,002$ & 8 & 9 \\
\hline 8 & & 30 & 15 & 15 & 1 & & & & & \\
\hline 9 & & 11 & 0 & 11 & 1 & & & & & \\
\hline 7 & & 5 & 4 & 1 & 0 & & & & & \\
\hline 3 & & 14 & 13 & 1 & 0 & & & & & \\
\hline
\end{tabular}




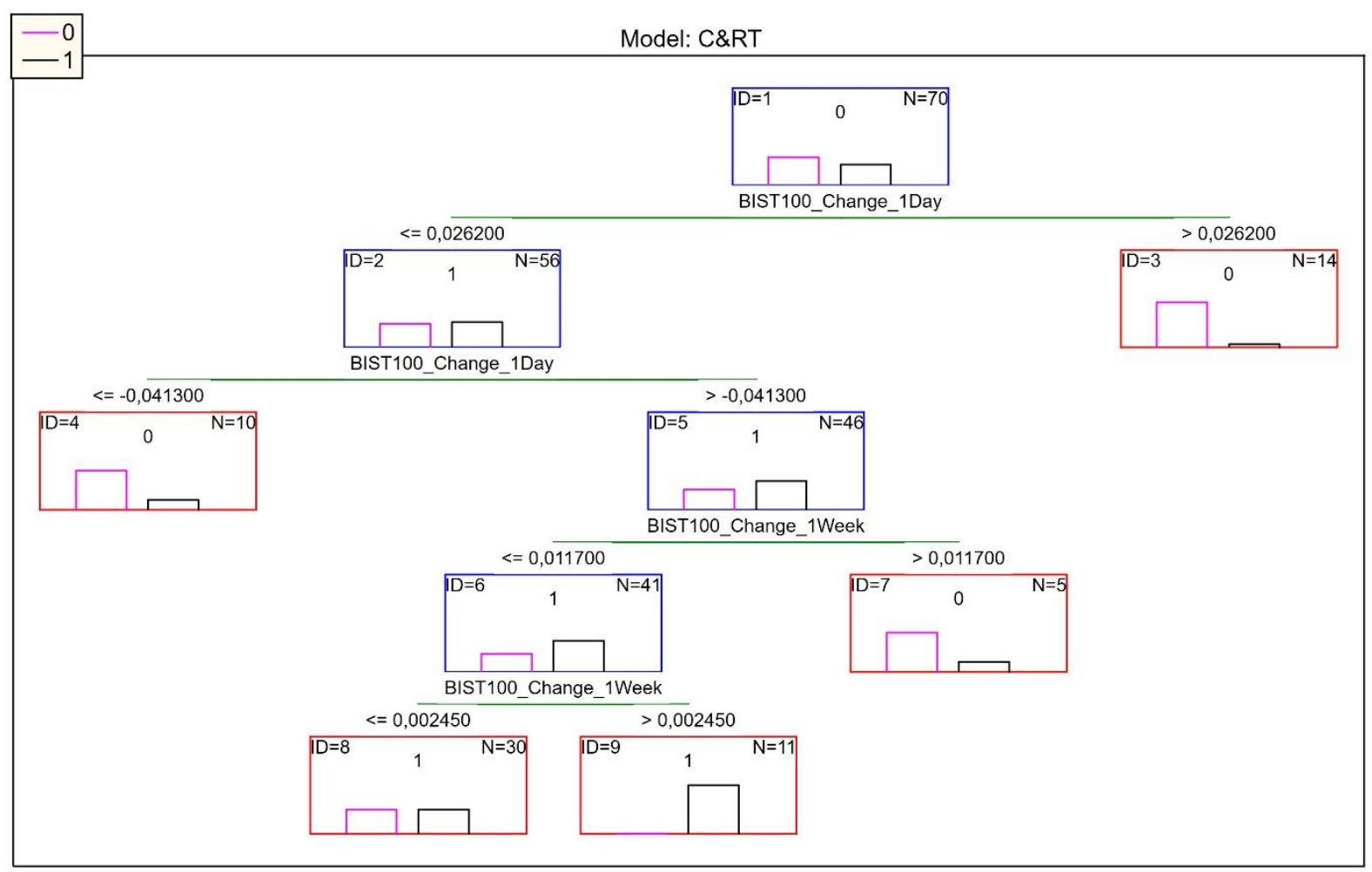

Şekil 2. C\&RT Modeli karar grafiği

C\&RT modeli, rasgele örnekleme metoduna göre belirlenen \%80 kontrol grubu üzerinde oluşturuldu ve değişkenler arası bağlantılar belirlendi. Elde edilen modelin başarısı benzer şekilde rasgele örnekleme metoduna göre belirlenen $\% 20$ test grubu üzerinde test edilmiştir. Kontrol ve test grupları kesişim kümesi boş küme olup, modelin test grubu üzerindeki doğruluk oranı \%76,47 olarak gözlemlenmektedir.

Tablo 6. C\&RT Model tahminlerine ait çapraz tablo

\begin{tabular}{|c|c|c|c|}
\hline \multirow{2}{*}{ Data: (Random 20\%)Testing Set } & \multicolumn{3}{|c|}{ Tahmin } \\
\cline { 3 - 4 } & 0 & 0 & 1 \\
\hline \multirow{2}{*}{ Gözlem } & 0 & 4 & 3 \\
\cline { 2 - 4 } & 1 & 1 & 9 \\
\hline
\end{tabular}

C\&RT modeline ait çapraz tablo Tablo 6'de paylaşılmıştır. İlgili matrisin diyagonal değerleri doğru olarak tahmin edilen gözlemlerin sayısını vermektedir.

\section{SONUÇLAR}

Bu çalışmada, FED faiz oranları ile BIST 100 günlük değer değişimleri arasındaki ilişki incelenmiştir. Bu amaçla, BIST 100 değerleri, FED faiz oranları açıklama tarihine göre, bir sonraki işlem günü, sonraki bir haftalık işlem günleri ve bir sonraki FED faiz açıklama tarihine kadarki işlem günleri dikkate alınarak üç ayrı periyotta incelenmiştir. Öncelikle, her bir zaman periyoduna göre bir sürekli değişken oluşturulmuştur. Sonrasında ise oluşturulan bu sürekli değişkenlere dayalı, ikili sınıfsal değişkenler üretilmiştir. Tüm bu değişkenlerin FED faiz oranlarıyla olan ilişkisini anlamlı şekilde gözlemleyebilmek için, C\&RT modeli 
oluşturulmuştur. Oluşturulan modele ait bağımlı değişken, FED oranlarından elde edilen ikili sınıfsal değişken olarak belirlenmiştir. Model FED oranlarının aşağı/yukarı yönlü hareketlerini \% 76,47 oranında doğru şekilde tahmin eden bir bağlantı gücüne sahiptir. Sonuç olarak, FED faiz oranlarının BIST 100 üzerindeki etkisinin bir sonraki işlem gününde sınırlı kaldığ 1 , bir haftalık süreçte etkisinin daha belirginleştiği ve daha sonra bu etkinin azalarak bir sonraki FED faiz oranları açıklamasına kadar devam ettiği gözlemlenmektedir.

Çalışmanın literatürdeki ilgili diğer çalışmalarla etkileşimi değerlendirildiğinde; Heiberger (2017) çalışmasında yer alan yönteme benzer bir karar ağacı yaklaşımı ile FED faiz değerlerindeki hareketlerin Türkiye'deki borsa hareketleri üzerindeki etkilerinin yön ve düzeyi incelenmiştir. Ek olarak, Hayford ve Malliaris (2008), çalışmasında FED faiz değerleri ile Amerikan borsası arasındaki ilişkiyi incelemiş ve herhangi bir ilişki tespit edememiştir. $\mathrm{Bu}$ çalışmada ise model bir gün sonraki borsa değerleri, bir haftalık borsa değerleri ve bir sonraki faiz açıklamasına kadar oluşan tüm borsa değerleri ayrı ayrı üç farklı zaman periyodunda incelenmiştir ve FED faiz değerlerinin BIST 100 üzerindeki etkisinin yalnızca haftalık periyotta önemli düzeyde yükseldiğini ve diğer iki periyot için ise etkinin sınırlı kaldığını gözlemlenmiştir. Bu açıdan değerlendirildiğinde, Hayford ve Malliaris'in modellerini genel bir zaman periyodu üzerine kurmaları, modellerin ilişkiyi değerlendirmede yetersiz kalmasını sağlamıştır. Bu çalışmada ilgili yaklaşım iyileştirilmiştir.

FED faiz artırım/indirim karar açıklama tarihleri ile BIST 100 endeksinde ortaya çıkan değer değişimlerin tamamını açıklayamaması çalışmanın kısıtları arasında yer almaktadır. $\mathrm{Bu}$ çalışma yatırımcıya, FED'in planlanmış takvim çerçevesinde açıklanan faiz dönemlerinde BIST 100 endeksinde oluşabilecek değişimler yönünde karar alma sürecinde yardımcı olabileceği düşünülmektedir. İleride yapılabilecek çalışmalar ise, FED'in ve diğer gelişmiş ülkelerin merkez bankalarının aldığı kararların gelişmekte olan ülke borsaları üzerinde etkileri incelenebilmesi mümkün olduğu gözlemlenmektedir.

\section{KAYNAKLAR}

Akbulut, Ramazan - Rençber, Ömer Faruk (2015), “BİST’te İmalat Sektöründeki İşletmelerin Finansal Performansları Üzerine Bir Araştırma", Muhasebe ve Finansman Dergisi, (Ocak). Ss.117-134

Aydın, Nurhan - Kayacan, Murad - Sayılır, Özlem- Taylan, Ali Sabri - Afşar, Aslı (2012), Borsaların Yapısı ve İşleyişi (1. Basım), Anadolu Üniversitesi Yayınları. No: 2532, Eskişehir.

Bahmani-Oskooee, Mohsen - Sohrabian, Ahmad (1992), "Stock Prices and the Effective Exchange Rate of the Dollar". Applied Economics, 24, pp. 454-464.

Breiman, Leo- Friedman, Jerome - Stone, Charles - Olshen, Richard (1984), Classification and Regression Trees.(1st. Edition), Chapman \& Hall'CRC. Taylor and Francis Group,

USA. (https://books.google.com.tr/books?id=gLs6DwAAQBAJ\&printsec=frontcover $\& h \mathrm{l}=\operatorname{tr} \&$ source $=\mathrm{gbs} \_g e \_s u m m a r y \_r \& c a d=0 \# \mathrm{v}=$ onepage $\& \mathrm{q} \& \mathrm{f}=$ false, 24.03 .2019$)$. 
Bernanke, Ben S. - Kuttner, Kenneth N. (2004), "What Explains the Stock Market's Reaction to Federal Reserve Policy?", Journal of Finance, 3 (60), pp.1221-1257,www. federalreserve.gov/pubs/feds/2004/200416/200416pap.pdf, (16.01.2019).

Bleich, Dirk- Fendel, Ralf - Rülke, Christoph J. (2013), "Monetary Policy and Stock Market Volatility", Deutsche Bundesbank Discussion Paper Series, no:45/2013, 33(3): pp.1669-1680.

Borsa İstanbul (2016), "BIST Pay Endeksleri Temel Kuralları”. (www.borsaistanbul. com/ docs/default-source/endeksler/bist-pay-endeksleri-temel-kurallari.pdf?sfvrsn= (10.02.2019).

Borsa İstanbul, (2018), "BIST Pay Endeksleri BIST 100”, www.borsaistanbul.com/ (16.01.2019).

Büberkökü, Önder (2008), "Hisse Senedi Fiyatları ile Döviz Kurları Arasındaki İlişkinin İncelenmesi: Gelişmiş ve Gelişmekte Olan Ülkelerden Kanıtlar”. İMKB Dergisi. Say1:52 ss. 1-18.

Çelik, Şaban- Erer, Deniz - Erer, Elif - Güleç, Tuna C.(2015), “TCMB Para Politikası Kararlarındaki Değişimlerin ve TCMB, FED Ve ECB Sözlü Yönlendirmelerin BIST 100 Oynaklığı Üzerindeki Etkisinin Analizi (2002-2014)”, Maliye Finans Yazıları 2015 - (103), ss.51-84.

Dornbusch, Rüdiger - Fischer, Stanley (1980), "Exchange Rates and Current Account". American Economic Review, 70, pp. 960-971.

Duran, Murat- Özlü, Pınar - Ünalmış, Deren, (2010), “TCMB Faiz Kararlarının Piyasa Faizleri ve Hisse Senedi Piyasaları Üzerine Etkisi”. Türkiye Cumhuriyet Merkez Bankası Ekonomi Notları, sayı: 8, ss.23-32.

Ehrmann, Michael - Fratzcher, Marcel (2009), “Taking Stock: Monetary Policy Transmission to Equity Markets”. Journal of Money, Credit and Banking, 4 (36), pp.719- 737.

Federal Reserve System (2019), "United States Fed Funds Rate". (https:// www.federalreserve.gov/monetarypolicy/openmarket.htm, (16.01.2019).

Fields, M. J. (1931), "StockPrices: A Problem in Verification", The Journal of Business of the University of Chicago, Vol. 4, pp. 415-418. (www.jstor.org/stable/2349652?seq= 1\#page_scan_tab_contents (16.01.2019).

Foan, Cengiz (2006), “İkincil Piyasalarda İşlem Gören Hisse Senetleri İçin Yatırım Kararlarına Yönelik Sistematik Bir Yatırım Yaklaşımı ve IMKB 30 Üzerine Bir Uygulama", İstanbul Üniversitesi Sosyal Bilimler Enstitüsü. Yayınlanmış Yüksek Lisans Tezi.

Frankel, Jeffrey Alexander (1983), Monetary and Portfolio Balance Model of Exchange Rate Determination in Economic Interdependence and Flexible Exchange Rates, JS Bhandai and B.H Putnam eds. MIT Press. Cambridge. 
Godollo, Hungary - Pécs, Hungary (2018), "Literature Review and Classification: Monetary Policy and Equity Market Volatility", Journal of Financial Studies \& Research Vol. 2018, Article ID 862384. (www.ibimapublishing.com/articles/JFSR/2018/862384/ (10.02.2019).

Grauwe, Paul D. (2008), "Stock Prices and Monetary Policy”, CEPS Working document. no: 304. Pp.1-22. (http://aei.pitt.edu/11658/1/1713.pdf (16.01.2019).

Gümüş Kurt, Gülizar. (2010), “Menkul Kıymet Piyasalarında Yabancı Yatırımcıların Etkisi İstanbul Menkul Kıymetler Borsası Örneği”, MKB Dergisi Cilt: 11 Sayı: 44. ss.61-96.

Hayford, March D. - Malliaris, Anastasios G. (2008), "Monetary Policy and the U.S. Stock Market”, Economic Inquiry. 3 (42), pp.387-401

Heiberger, Raphael. (2017), "Predicting economic growth with stock networks." Physica A: Statistical Mechanics and its Applications, 489, 10.1016/j.physa.2017.07.022, pp. 102111 .

Kashefi, Javad. (2008), "The Effect of Changesin the Federal Funds Rate on Value and Growth Stock Prices: A Threshold GARCH Approach", International Research Journal of Finance and Economics, 17, pp.129-143

Lee, Chih. W. - Chang, Ming J. (2011), “Announcement Effects and Asymmetric Volatility in Industry Stock Returns: Evidence from Taiwan”, Emerging Markets Finance \& Trade 47 (2), pp.48-61

Lobo Bento J. (2000), “Asymmetric Effects of Interest Rate Changes on Stock Prices”. The Financial Review, Eestern Finance Association 35, pp.125-144.

Lucey, M. Brian. (2000), “Anomalous Daily Seasonality in Ireland?”, Applied Economics Letters, Vol. 7, Issue 10, pp. 637-640.

Michlian, Stefan B.(2014), The Impact of Short-term Interest Rate on Stock Prices in the Czech Republic. Institute of Economic Studies Faculty of Social Sciences Charles University in Prague, Master Thesis, (file:///C:/Users/PC/Downloads/DPTX_2012_2_11230_0__387896_0_138180.pdf, (18.01.2019).

Rigobon, Roberto - Sack, Brian. (2003), "Measuring the Response of Monetary Policy to the StockMarket”, The Quarterly Journal of Economics, 118, issue 2, pp.639-669.

Sayman, Yahya (2006), Hisse Senetleri İMKB'de İşlem Gören İmalat İşletmeleri Açısından Nakit Yönetimini Etkileyen Faktörler, Ankara Üniversitesi, Sosyal Bilimler Enstitüsü. Yayınlanmış Yüksek Lisans Tezi

Şahin, Baki C. (2011), Para Politikası Kararlarının Hisse Senedi Piyasası Üzerine Etkisi: Türkiye Uygulamas1, TCMB Uzmanlık Yeterlilik Tezi, www3.tcmb.gov.tr /kutuphane/TURKCE/tezler/bakicemsahin.pdf (19.01.2019) 
Şahin, Özkan. (2014), BİST'teki Endekslerin Volatilitelerinin Karşılaştırmalı Analizi: BİST Kurumsal Yönetim, BİST 100, BİST 50 ve BİST 30 Endeksleri Üzerinde Bir Uygulama, Yayınlanmış Doktora Tezi. Düzce Üniversitesi, Sosyal Bilimler Enstitüsü. Düzce

Thorbecke, Willem. (1997), “On Stock Market Returns and Monetary Policy”, Journal of Finance. 5 (67), Pp.981-990. (www.onlinelibrary.wiley.com/doi/pdf/10.1111/j.15406261.1997.tb04816.x (19.01.2019)

Tokmakçığlu, Kaya (2017), "The Relatıonshıp Between Dıversıfıcatıon And Volatılıty In The Share Prices: Evıdence From BIST", Kırklareli Üniversitesi İktisadi ve İdari Bilimler Fakültesi Dergisi (ISSN: 2146-3417 / E-ISSN: 2587-2052) Y1l: 2017 , Cilt: 6, - Sayı: 2. ss.102-120

Varlık, Batu (2017), Borsa İstanbul'da (BİST) Hisse Senedi Fiyatlarının Spektral Analizi. Yayınlanmış Yüksek Lisans Tezi, Adnan Menderes Üniversitesi Sosyal Bilimler Enstitüsü Adana

Yucel, Ahmet (2016), Predictive Text Analytics and Text Classification Algorithms, PhD Dissertation, Auburn University, USA.

Zare, Roohollap- Azali M. - Habibullah. M.S. (2013), "Monetary Policy and Stock Market Volatility in the ASEAN5: Asymmetries over Bull and Bear Markets", Procedia Economics and Finance, ScienceDirect 7: pp.18-27, www.ac.els-cdn.com/S221256711 300213X/1-s2.0-S221256711300213X-main.pdf?_tid=db640592-f1bf-4595-992edb60 9d86b985\&acdnat=1547662751_6aaf53aaebe38e9b035e5102fd00a2a5 (20.01.2019).

Zhang, Cheng-si- Zhang, Da-yin - Breece, Jeffery (2011), "Financial Crisis, Monetary Policy and Stock Market Volatility in China", Annals of Economics and Finance 12(2): pp.371-388 